\title{
THE EFFECT OF SERPASIL IN PULMONARY HYPERTENSION
}

\author{
BY \\ D. HALMAGYI,* B. FELKAI, Z. CZIPOTT, AND G. KOVÁCS \\ From the Medical and Surgical Cardiovascular Division, of the First Department of Medicine, University Medical \\ School, Szeged, Hungary \\ Received April 15, 1956
}

A considerable amount of information has been accumulated concerning the effect of various hypotensive agents on the pulmonary circulation. A detailed account on these observations was given recently by one of us (Halmagyi, 1957). Most of these studies were carried out in patients suffering from mitral stenosis. It was concluded that the increase of pulmonary vascular resistance in this disease is due both to organic changes and to vasoconstriction, the latter being mediated by the nervous system (Halmagyi et al., 1953). No uniform action was, however, obtained by drugs acting on different parts of the nervous system: even similar-acting drugs had a different effect on the pulmonary circulation. Tetra-ethylammonium (Halmagyi et al., 1953; Scott et al., 1955), dibenamine, sodium nitrite, and sleep (Halmagyi et al., 1953) resulted in a decrease in pulmonary arterial pressure and resistance. On the other hand, hexamethonium failed to influence pulmonary vascular resistance in carefully controlled observations carried out in patients suffering from mitral stenosis (Storstein and Tveten, 1954).

There were many disadvantages in the therapeutic use of the substances mentioned above. The necessity of a parenteral rout of administration, their rapid excretion and, last but not least, their strong hypotensive action on the systemic circulation discouraged their widespread use. Schumann $(1954,1955)$ has recently pointed out that long-term peroral administration of serpasil to patients suffering from mitral stenosis resulted in an apparent amelioration of their complaints. This effect was attributed by him to general sedation and bradycardia, brought about by this medicament. It was therefore decided to investigate the effect of serpasil on the lesser circulation.

\section{MATERIAL AND METHODS}

Fifteen patients, aged 17 to 45 years, were investigated. All were submitted for assessment of the need for surgical treatment of their heart disease. None was in manifest heart failure at the time of observation. All the patients shown in Table I suffered from mitral stenosis with the exception of Case 2 (isolated pulmonary stenosis of slight degree), Case 4 (patent ductus arteriosus), and Case 13 (ventricular septal defect with pulmonary hypertension).

Cardiac catheterization was performed in the usual manner as described before (Halmagyi et al., 1952 and 1953). No sedation was given: apprehensive patients were considered unsuitable for this kind of observation. The tip of the catheter was placed in the pulmonary artery and an arterial cannula was placed in the femoral or brachial artery. Both procedures were done under local anæsthesia. A sufficient time was allowed then for stabilization.

Pulmonary " capillary" pressures were obtained. Blood was withdrawn in all cases from the catheter tip in this position. The catheter was then withdrawn to the main pulmonary artery under

* Present address: Miners' Chest Disease Treatment Centre, Llandough Hospital, Cardiff. 
TABLE I

The Effect of Serpasil on the Lesser Circulation in Pulmonary Hypertension of Various Origin

\begin{tabular}{|c|c|c|c|c|c|c|c|c|c|c|c|c|c|c|c|}
\hline \multirow[t]{2}{*}{ No. } & \multirow[t]{2}{*}{$\begin{array}{l}\text { Ref. } \\
\text { No. }\end{array}$} & \multicolumn{2}{|c|}{$\begin{array}{c}\text { Cardiac } \\
\text { index, litres }\end{array}$} & \multicolumn{2}{|c|}{$\begin{array}{l}\text { Pulmonary } \\
\text { arterial } \\
\text { pressure }\end{array}$} & \multicolumn{2}{|c|}{$\begin{array}{l}\text { Pulmonary, } \\
\text { capillary " } \\
\text { pressure }\end{array}$} & \multicolumn{2}{|c|}{$\begin{array}{l}\text { Femoral } \\
\text { arterial } \\
\text { pressure }\end{array}$} & \multicolumn{2}{|c|}{$\begin{array}{l}\text { Pulmonary } \\
\text { arteriolar } \\
\text { resistance }\end{array}$} & \multicolumn{2}{|c|}{$\begin{array}{l}\text { Total } \\
\text { pulmonary } \\
\text { resistance }\end{array}$} & \multicolumn{2}{|c|}{$\begin{array}{l}\text { Peripheral } \\
\text { arterial } \\
\text { resistance }\end{array}$} \\
\hline & & B & $\mathbf{A}$ & B & $\mathbf{A}$ & B & $\mathbf{A}$ & B & A & B & A & B & $\mathbf{A}$ & B & $\mathbf{A}$ \\
\hline 1 & 284 & 3.60 & $4 \cdot 20$ & 11 & 9 & 7 & 6 & 87 & 90 & 89 & 57 & 244 & 171 & 1935 & 1757 \\
\hline 2 & 213 & 3.55 & 2.58 & 14 & 11 & 9 & 6 & 100 & 90 & 112 & 155 & 316 & 341 & 2260 & 2760 \\
\hline 3 & 306 & $3 \cdot 20$ & $3 \cdot 20$ & 16 & 14 & 11 & 12 & 100 & 90 & 126 & 50 & 400 & 350 & 2500 & 2250 \\
\hline 4 & 348 & $5 \cdot 88^{*}$ & - & 21 & 21 & 16 & 16 & 87 & 87 & 68 & - & 286 & - & 2000 & - \\
\hline 5 & 292 & $4 \cdot 25$ & 5.00 & 22 & 17 & 14 & 11 & 105 & 105 & 150 & 96 & 414 & 272 & 1978 & 1678 \\
\hline 6 & 309 & 3.86 & $3 \cdot 17$ & 22 & 16 & 19 & 15 & 100 & 100 & 62 & 25 & 456 & 404 & 2070 & 2520 \\
\hline 7 & 330 & 4.09 & $3 \cdot 23$ & 24 & 20 & 16 & 9 & 90 & 82 & 157 & 272 & 472 & 496 & 1762 & 2035 \\
\hline 8 & 282 & - & - & 25 & 25 & 22 & 15 & 120 & 120 & - & - & - & - & - & - \\
\hline 9 & 298 & 1.83 & $2 \cdot 61$ & 27 & 31 & 21 & 24 & 90 & 90 & 262 & 214 & 1180 & 950 & 3940 & 2760 \\
\hline 10 & 349 & $6 \cdot 34$ & 6.08 & 32 & 21 & 24 & 17 & 105 & 102 & 101 & 39 & 406 & 263 & 1330 & 1350 \\
\hline 11 & 324 & $2 \cdot 53$ & $2 \cdot 20$ & 39 & 29 & 31 & 30 & 82 & 79 & 224 & 34 & 1230 & 1055 & 2580 & 2870 \\
\hline 12 & 317 & 2.81 & $2 \cdot 81$ & 40 & 40 & 34 & 34 & 105 & 98 & 170 & 170 & 1285 & 1285 & 3100 & 2790 \\
\hline 13 & 335 & $5 \cdot 43^{*}$ & $6.93^{*}$ & 58 & 33 & 3 & 3 & 90 & 100 & 810 & 348 & 870 & 381 & 2300 & 2660 \\
\hline 14 & 350 & 2.89 & 2.98 & 66 & 31 & - & - & 110 & 110 & - & - & 1828 & 808 & 3050 & 2870 \\
\hline 15 & 333 & 3.51 & 3.51 & 72 & 59 & 36 & 36 & 100 & 95 & 822 & 525 & 1640 & 1340 & 2280 & 2160 \\
\hline
\end{tabular}

All pressures represent mean pressures, expressed in $\mathrm{mm}$. Hg. Resistances are given in dyne sec. $\mathrm{cm} .{ }^{-5 m} .{ }^{2}$ B.S.A. Flow values signed with * represent pulmonary flow.

$B=$ before, $A=30$ min. after serpasil.

fluoroscopic guidance. Pulmonary and femoral arterial pressures were then measured. All pressures were taken with Sanborn electromanometers and recorded on a multichannel oscillograph. Cardiac outputs were determined by the direct Fick method. Oxygen consumption was measured by using a Noyons-type of diapherometer (Kipp, Delft). During this procedure, simultaneous blood samples were obtained from the pulmonary artery and the femoral or brachial artery. The blood samples were analysed for oxygen by a whole-blood oximeter of the hæmoreflector-type (Kipp, Delft). Hæmoglobin content was determined photoelectrically.

The above procedures were followed by injecting $1 \mathrm{mg}$. of serpasil into the catheter in a period of four minutes. Pulmonary arterial, pulmonary "capillary ", and femoral arterial pressures and cardiac output were measured in every tenth minute repeatedly. In measuring pulmonary capillary pressure the catheter was wedged apparently in the same site on each occasion. Forty minutes following the injection of the drug, the observation was terminated.

Mean pressures were obtained by electric integration. The zero point for all measurements was $10 \mathrm{~cm}$. anterior to the back, with the patient recumbent. Pulmonary arteriolar resistance, total pulmonary resistance, and systemic resistance were calculated according to the well known formulae. 
RESULTS

Our detailed results are shown in Table I; only some main features are emphasized below. Since a significant change in heart rate never occurred, its values were omitted from the table which contains the individual cases arranged in the order of the level of pulmonary arterial pressure.

In mitral stenosis, administration of serpasil was followed by a decrease of pulmonary arterial pressure and resistance. In most cases pulmonary "capillary" pressure remained unchanged. No change occurred in systemic arterial pressure and resistance, and cardiac output remained generally identical. The mean changes are illustrated in Fig. 1. Mean diminution of pulmonary arterial pressure and resistance amounted to 30 per cent, and that of total pulmonary resistance to 23 per cent. Pulmonary resistance increased in Case 7, and remained unchanged in Case 12. In the former the simultaneous presence of tricuspid stenosis was established, while the latter patient died three weeks after mitral valvotomy as a consequence of recurrent pulmonary embolism and an obstructing thrombosis of the left atrium.

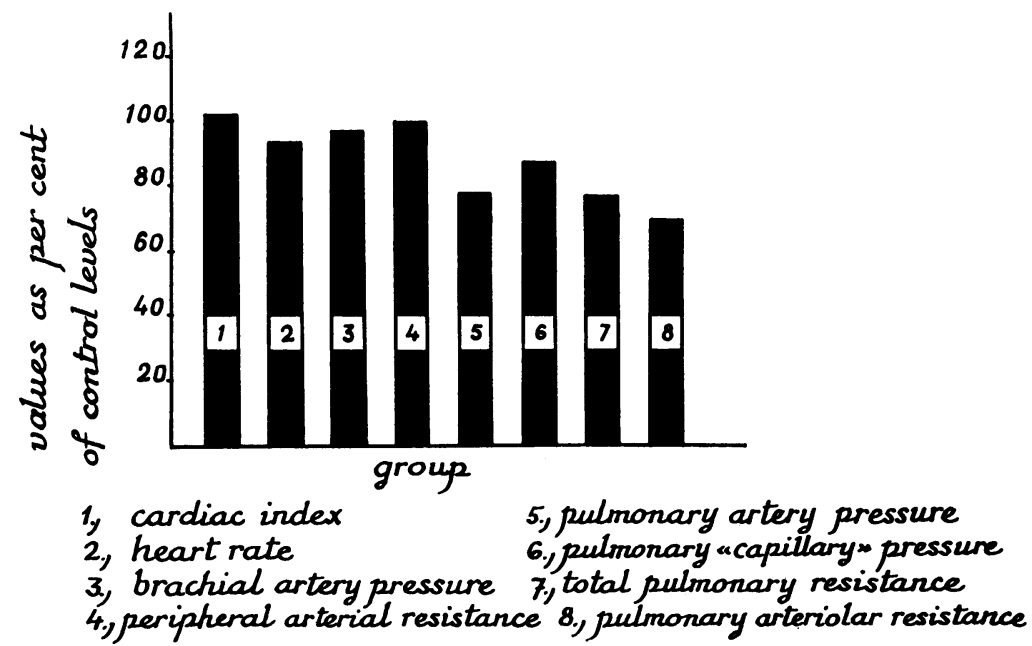

FIG. 1.-Mean change of hæmodynamic data in 12 patients suffering from mitral stenosis following the administration of serpasil. Control values are indicated as 100 per cent.

Serpasil failed to influence pulmonary arterial pressure and resistance in pulmonary stenosis (Case 2) and in patent ductus arteriosus (Case 4).

A 50 per cent reduction in pulmonary arterial pressure and resistance followed the administration of serpasil in a patient suffering from ventricular septal defect complicated by pulmonary hypertension (Case 13). At the same time systemic pressure and resistance increased. Thus the increase of pulmonary flow occurred at the expense of systemic flow.

Lowering of pulmonary arterial pressure and resistance never occurred earlier than 20 minutes after the injection of serpasil. No attempt was made to investigate the effect of larger doses or to observe the duration of the effect. In no case did the patients experience any discomfort following the injection of serpasil.

\section{Discussion}

In mitral stenosis, administration of $1 \mathrm{mg}$. of serpasil resulted in a significant decrease of pulmonary arterial pressure, pulmonary capillary pressure remaining unchanged. This indicates that while the level of pulmonary capillary pressure is due entirely-or nearly entirelyto anatomical and hydrodynamic factors, the level of pulmonary arterial pressure is significantly influenced by constriction of the pulmonary vascular tree. This vasoconstriction is at least in 


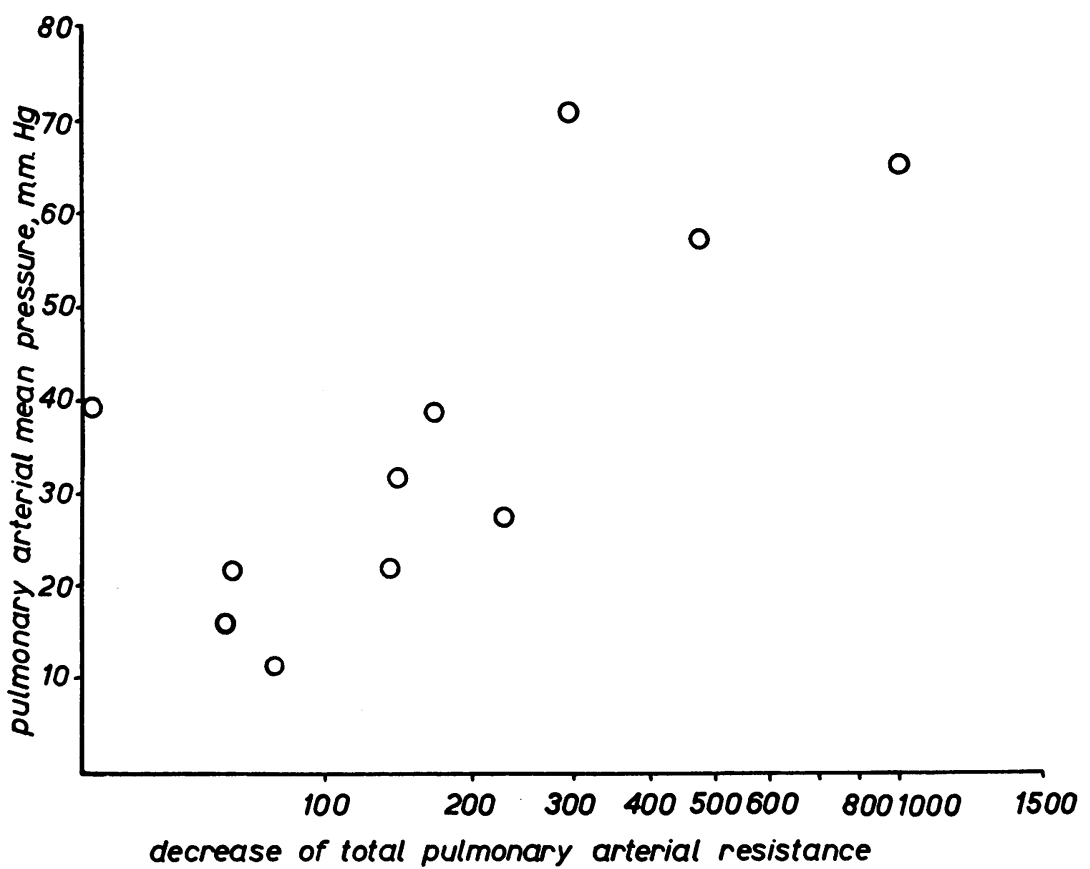

Fig. 2.-Relationship of initial value of pulmonary arterial mean pressure and serpasilinduced decrease of total pulmonary resistance.

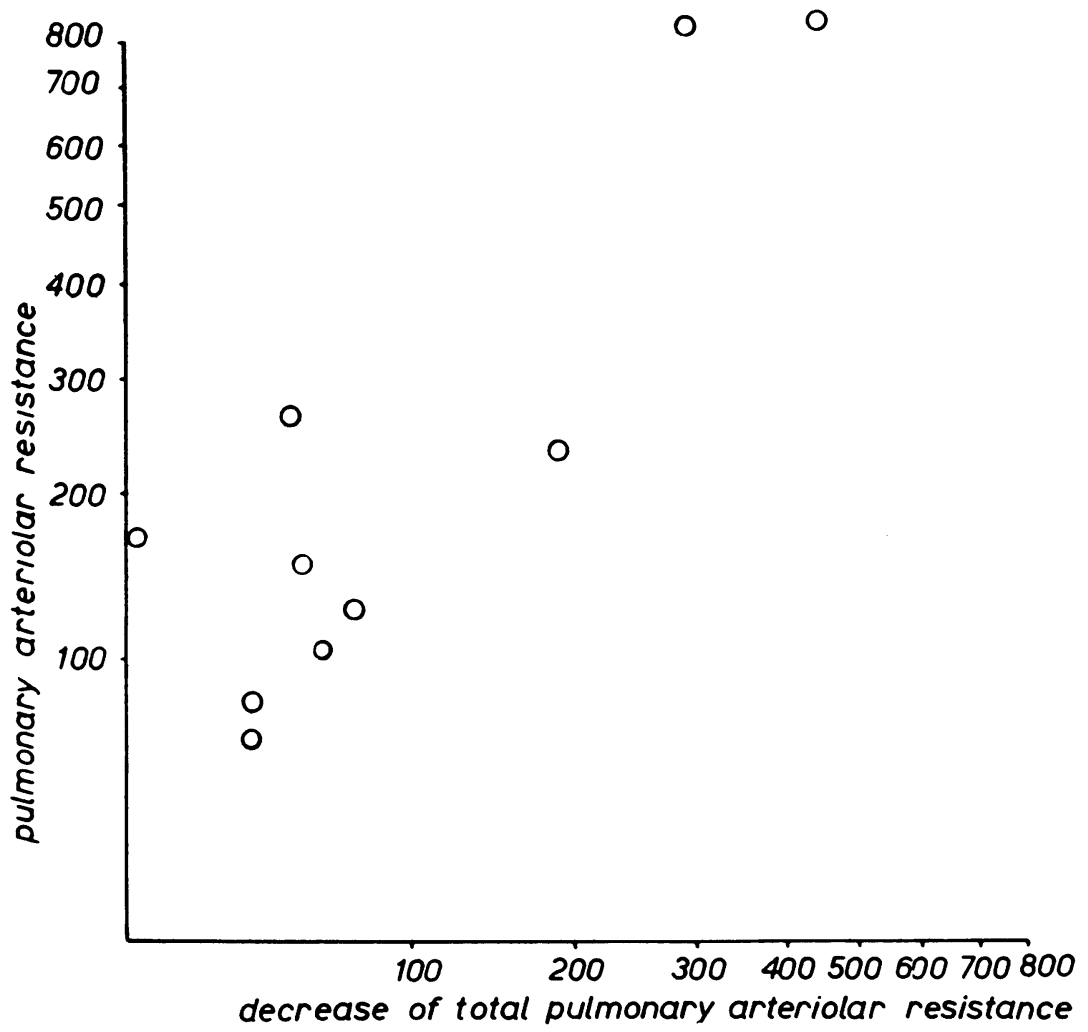

FIG. 3.-Relationship of initial value of pulmonary vascular resistance and its decrease following the administration of serpasil. 
part inhibited by serpasil. If pulmonary arterial pressure is normal, as in our case of pulmonary stenosis (Table I, Case 2), or if pulmonary hypertension is due to an increased flow, as in our case of patent ductus arteriosus (Table I, Case 4), serpasil remains ineffective.

The remarkable drop of pulmonary arterial pressure and resistance in a case of ventricular septal defect may have important physiological and therapeutic implications.

Pulmonary vascular resistance may increase tremendously in some cases of congenital heart disease. This increased resistance in the lesser circuit is generally presumed to be a consequence of organic obliteration of the pulmonary vascular tree. These patients respond very poorly to surgical correction of the underlying anomaly: they have to be treated conservatively. Injecting acetylcholine in a patient suffering from patent ductus arteriosus with pulmonary hypertension, Harris (1955) observed a great fall in pressure in the pulmonary artery. A similar effect was obtained in this disease following the administration of priscoline by Denoline et al. (1952) and London et al. (1955). Priscoline given to a patient with atrial septal defect complicated by pulmonary hypertension resulted in a large decrease of pulmonary vascular resistance and an increase of pulmonary pressure and flow (Dresdale et al., 1954). It seems therefore that pulmonary hypertension in the above types of congenital heart disease is due at least in part to vasoconstriction controlled by the nervous system. Further work is needed to elucidate the real significance of serpasil in the treatment of these conditions.

The extent of serpasil-induced decrease of pulmonary resistance was in most cases proportional to the initial level of pressure and resistance in the lesser circulation. This relationship is illustrated in Fig. 2 and 3. The appearance of a beneficial effect may be expected therefore especially in severe cases of pulmonary hypertension.

It remains uncertain whether unresponsiveness to serpasil, as in our Cases 7 and 12 is due to real drug-resistance or simply to insufficient dosage. As mentioned before, Case 12 died following valvotomy. Scott et al. (1955) advanced the hypothesis that a significant fall in pulmonary artery pressure after administration of tetraethylammonium chloride in a patient with mitral stenosis preoperatively is a good prognostic sign.

Serpasil had in our cases a remarkably elective effect on the lesser circulation. This was especially striking in our case of ventricular septal defect with pulmonary hypertension (Case 13). This is, however, in no way contradictory to earlier observations and means only that serpasil-as well as other hypotensive substances-acts mainly on constricted vessels irrespective of their belonging to the systemic or pulmonary circulation.

The pulmonary hypotensive effect of serpasil appears 20-30 minutes following its intrapulmonary administration. This long latency does not speak in favour of a direct vascular action. It is suggested that serpasil exerts its action by influencing the nervous system. A further possibility is that the action on the lesser circulation is not from serpasil itself but from one of its metabolites. A paper by Angelino and Levi (1956), who also observed a fall in pulmonary arteriolar resistance after the administration of serpasil in cases of mitral stenosis, has come to our notice since this paper was submitted.

\section{SUMMARY}

The effect of the parenteral administration of $1 \mathrm{mg}$. of serpasil was investigated in subjects suffering from pulmonary hypertension.

In mitral stenosis a significant decrease of pulmonary arterial pressure, pulmonary vascular and total pulmonary resistances occurred. Pulmonary capillary pressure, and systemic arterial pressure and resistance remained unchanged.

A 50 per cent lowering of pulmonary arterial pressure and resistance occurred in a case of ventricular septal defect with pulmonary hypertension.

Systemic arterial pressure and resistance, being initially normal in all patients of this series, remained uninfluenced by serpasil. The drug acted in these cases exclusively on the lesser circulation, i.e. on that part of the vascular bed in which vasoconstriction existed. 
As it may be given by mouth, and as it is fairly well tolerated, serpasil may have some therapeutic significance in certain cases of pulmonary hypertension.

Our thanks are due to Messrs. Ciba, Basle, for a generous supply of serpasil. Miss I. Szabó rendered invaluable help and assistance throughout these experiments.

\section{REFERENCES}

Angelino, P. F., and Levi, V. (1956) Minerva Cardioangiologica, 4, 174.

Denolin, H., Lequime, J., and Segers, M. (1952). Cardiologia, 21, 1.

Dresdale, D. T., Michtom, R. J., and Schultz, M. (1954). Bull. N.Y. Acad. Med., 30, 195.

Halmagyi, D. F. J. (1957). Klinische Physiologie des kleinen Kreislaufs. Fischer, Jena.

—, Felkai, B., Iványi, J., and Hetényi, Jr., G. (1952). Brit. Heart J., 14, 101.

$-,-\frac{}{\mathrm{P}}, \frac{\mathrm{Z}}{\mathrm{H}}$, Zótér, T., Tényi, M., and Szücs, Zs. (1953). Brit. Heart J., 15, 15.

Harris, P. (1955). Brit. Heart J., 17, 85.

London, F., Stevenson, T. D., Morrow, A. G., and Haller, J. A. (1955). Circulation, $12,742$.

Schumann, H. (1954). Ztschr. Kreislauff., 43, 614.

(1955). Klin. Wschr., 33, 124.

Scott, R. C., Kaplan, S., and Stiles, W. J. (1955). Amer. Heart J., 50, 720.

Storstein, O., and Tveten, H. (1954). Scand. J. Clin. Lab. Invest., 6, 169. 